\title{
Sabotage in contests: a survey
}

\author{
Subhasish M. Chowdhury ${ }^{1} \cdot$ Oliver Gürtler $^{2}$
}

Received: 28 September 2014/ Accepted: 9 May 2015/Published online: 26 June 2015

(C) The Author(s) 2015. This article is published with open access at Springerlink.com

\begin{abstract}
A contest is a situation in which individuals expend irretrievable resources to win valuable prize(s). "Sabotage" is a deliberate and costly act of damaging a rival's likelihood of winning the contest. Sabotage can be observed in, e.g., sports, war, promotion tournaments, and political or marketing campaigns. In this article, we provide a model of, and different perspectives on, such sabotage activities and review the economics literature analyzing the act of sabotage in contests. We discuss the theories and evidence emphasizing the means of sabotage, why sabotage occurs, and the effects of sabotage on individual contestants and on overall welfare, with possible means of reducing sabotage. We note that most sabotage activities are aimed at the ablest contestant, the possibility of sabotage reduces productive effort exerted by the contestants, and sabotage may lessen the effectiveness of public policies, such as affirmative action, or information revelation in contests. We discuss the different policies a designer might use to counteract sabotage. We conclude by pointing out some areas of future research.
\end{abstract}

Keywords Contest $\cdot$ Tournament $\cdot$ Sabotage $\cdot$ Survey

JEL Classification $\mathrm{C} 72 \cdot \mathrm{C} 91 \cdot \mathrm{C} 92 \cdot \mathrm{D} 72 \cdot \mathrm{D} 74 \cdot \mathrm{M} 51 \cdot \mathrm{M} 52$

The king may be threatened by dangers in the interior or in the remote regions, particularly when he is about to start on an expedition. An internal rebellion is one led by a Crown Prince, the Purohita (the priest), the chief of defence or a minister... An internal rebellion is more dangerous than one in the outer regions because it is like nurturing a viper in one's bosom.

- Kautilya, Artha Shastra [Economic Science], c. 4th Century BC, p. 160

Subhasish M. Chowdhury

s.modak-chowdhury@uea.ac.uk

1 University of East Anglia, Norwich, England, UK

2 University of Cologne, Cologne, Germany 


\section{Introduction}

Sabotage is ubiquitous in everyday life. A very early mention of sabotage was by Kautilya, the Prime Minister of Chandragupta Maurya (the first King of the Maurya Kingdom in ancient India) in $400 \mathrm{BC}$. The Cambridge Dictionary defines sabotage as "to damage or destroy equipment, weapons or buildings in order to prevent the success of an enemy or competitor". In the context of labor economics, Lazear (1989, p. 563) defines sabotage as "any (costly) actions that one worker takes that adversely affect the output of another". Although the concept of sabotage is quite familiar, the day-to-day definitions and understandings of sabotage vary across contexts, places, and times. In the industrial organization literature, sabotage is connected with the act of "raising rival's cost" (Salop and Scheffman 1983). The early literature on labor issues considers sabotage to be the intentional use of low efficiency by laborers in response to low wages offered (Pouget 1912). ${ }^{1}$ In each of these cases, individuals use strategies intended to damage someone else's success rather than improving their own. Sabotage has a similar connotation in contests. A deliberate and costly act by one contestant to damage the performance of another in a contest is, in general, termed sabotage. In this study we review the economics literature on sabotage from the perspective of contests.

Formally, contests are situations in which participants expend costly resources to win a valuable prize and, irrespective of the outcome, all of the resources expended are lost. Examples of such situations include sports, lobbying, job interviews, promotion tournaments, research funding applications, legal disputes, war, patent races, and advertising. In each of these circumstances, contestants have the opportunity to expend resources to improve their own probability of winning the prize. Often, they also have the opportunity to expend resources to reduce another contestant's probability of winning the same prize. Following a major part of the literature, we term the resources expended to increase one's own probability of winning as "effort", and those expended to reduce rivals" probability of winning as "sabotage". Because the participants" winning probabilities always sum to 1 , sabotage indirectly improves one's likelihood of winning the prize. ${ }^{2}$ However, this type of behavior often violates social norms and is illegal and costly-making sabotage an expensive strategy. Despite this, such behavior is widespread, as the following examples indicate:

- The steady decline of Microsoft since 2000 under CEO Steve Ballmer is attributed partly to the new employee review system introduced by him (Oremus 2013). In this system, employees are evaluated relative to each other, top performers receive bonuses and promotions whereas those at the bottom often have to fear for their jobs. The review system encourages employees to do almost everything they can to improve their ranking relative to their peers. For instance, a Microsoft engineer reported that "people responsible for features will openly sabotage other people's efforts". Sabotage was undertaken subtly by withholding information from colleagues to ensure that they did not get ahead in the rankings.

- Businesspeople often resort to costly strategies to damage competitors' business. Friedman (1998, p. 577) describes one such business malpractice that occurred in the 1890s. John H. Patterson, the owner of the National Cash Register Company, used a

\footnotetext{
1 Veblen (1921, p. 38) defines sabotage as the "conscientious withdrawal of efficiency."

${ }^{2}$ Here, we do not consider cases in which there might be a tie or no winner is selected. The intuition behind sabotage, however, remains the same for such cases.
} 
special type of a counterproductive salesman. They were not required to promote their own product; instead, their job was to follow the salesmen of rival firms from shop to shop and to convince the customers to cancel any order that had just been placed. In this way, the market remained open for Patterson to sell his own cash registers in the near future.

- In many marketing campaigns, firms stress their rivals' weak points. One such example is Progresso's famous advertisements, which highlighted that its rival Campbell's offered 95 soups containing monosodium glutamate (MSG). This led to a 4-5\% decline in Campbell's US soup sales (Lubin 2011).

- Sabotage is common also in political campaigns in which the opponents are discredited and often denigrated. In the 1997 general election cycle, the UK's Conservative Party broadcast an advertisement with a picture of the Labor Party leader Tony Blair, replacing his eyes in the picture with demonic ones.

- Political imprisonment can be seen as an extreme form of such sabotage in political contests. As an example, consider Aung San Suu Kyi, who was placed under house arrest in 1990 when her National League for Democracy received $59 \%$ of the votes in the Burmese general election.

- Stealing crucial information from a political or commercial rival is also not uncommon. One such example is the set of events that led to the "Watergate scandal" in 1972. US President Nixon and the Committee for the Re-Election of the President designed a plan that involved, among other illegal activities, breaking into the Democratic National Committee headquarters at the Watergate complex to collect information that could be used against the Democratic Party in the election.

- "Scorched earth" is a famous strategy in warfare and corporate takeover battles. In warfare, it involves troops burning any land, crops, or trees as they retreat so there are no supplies available to the advancing enemy army. In corporate takeover battles, the strategy describes actions that a firm undertakes to make the proposed takeover unattractive to the acquiring firm, such as liquidating its valuable and desirable assets and assuming new debt obligations.

- Female satin bowerbirds view bowers, i.e., decorated nests, as indicators of male quality in mate choice. As a consequence, male satin bowerbirds often destroy the bowers of other males to gain an advantage in sexual competition (Borgia 1985).

All of these examples, although in a variety of different contexts, convey essentially the same message. However, because these examples often resemble other seemingly similar contest-driven behavior, it is important to distinguish acts of sabotage from such behavior as "punishment" (Abbink et al. 2010), "nastiness" (Zizzo and Oswald 2001; Abbink and Sadrieh 2009), "risk taking" (Genakos and Pagliero 2012), and "cheating" (Preston and Szymanski 2003). The main difference is that sabotage is conducted to damage others and is driven by material benefits for the saboteur.

When an agent punishes someone else, this typically happens either because the person being punished is not following an objective norm or because the agent is motivated by fairness issues. Unlike sabotage, the punishment oftentimes is not executed in expectation of a material benefit for the punisher. It is to be noted, however, that when a norm is subjective, a powerful agent may distort the norm in his or her own favor, making punishment and sabotage indistinguishable. This is what happened when the military junta in power "punished" Suu Kyi with imprisonment. However, in the end, it was an act of sabotage. 
Agents who indulge in nastiness - as in the joy of destruction (Abbink and Sadrieh 2009) or in money-burning (Zizzo and Oswald 2001) games-may execute strategies similar to those of a saboteur. However, although there might be intrinsic motivation for being nasty, employing that strategy does not necessarily produce a material benefit for the agent. Instead, sabotage behavior is motivated by the expected material benefit arising from raising the incremental probability of winning.

Similarly, an agent's risky behavior may or may not involve other agents, especially competitors. Although engaging in sabotage itself may be risky, to use sabotage there needs to be a victim of sabotage, which is not a pre-condition for risky behavior.

The distinction from cheating, however, is not that clear. Oftentimes, an agent involved in cheating does so to illegally distort his own performance in a contest. A sabotaging agent tries (legally or illegally) to damage the performance of his rivals. Preston and Szymanski (2003) analyzed several forms of cheating in sports and mention that those cheating activities, such as taking illegal performance-enhancing drugs, doping racehorses, and intentional poor performance in a basketball game, are not sabotage. There are, however, other cheating acts that are inseparable from the act of sabotage. When an agent illegally damages the opponent, it becomes both cheating and sabotage. One such example comes from boxing. In a 1962 heavyweight title fight, it is claimed that Sonny Liston applied a banned substance to the surface of his gloves that caused irritation to the eyes of the opponent Muhammad Ali (then known as Cassius Clay). Use of such an illegal substance was cheating, but because it hindered Ali's performance, it also was an act of sabotage. $^{3}$

Because sabotage is common, important, and different from other similar acts, research has continuously investigated the means and consequences of sabotage. However, there is no comprehensive survey of existing studies. Partial reviews of sabotage behavior, as parts of longer reviews, are provided by (Konrad 2009, Chapter 5.3), on the theoretical literature, and by (Dechenaux et al. 2012, Chapter 6.1), on the experimental literature. In addition, Amegashie (2015) recently provided a brief overview of sabotage in rent-seeking contests. In this study, we thoroughly review the economics literature of sabotage in contests, both in theoretical and applied terms. We cover the economics literature but do not consider literature from other areas of research, such as organizational behavior or political science, even though they might be related in terms of broader appeal.

The remainder of this survey is arranged as follows. In the next section, we provide a general specification of contests without sabotage and then introduce sabotage into this framework. Next, we discuss the consequences and welfare effects of agents engaging in sabotage, for the contest organizer and for third parties. Saboteurs may be discouraged in two main ways: reducing the benefits of sabotage or increasing its costs. We discuss these issues in detail and introduce examples. We conclude by pointing out possible research contributions that are yet to be made.

\section{Contests without sabotage}

From a game-theory perspective, most contests are two-stage games. In the first stage, the contest organizer sets the "rules of the game", for example the structure of prizes, participation costs, number of contestants, and so on. The contestants observe these rules and

${ }^{3}$ We thank Atsu Amegashie for providing us with the example. 
choose their competitive activities in the game's second stage. ${ }^{4}$ The early contest literature (Tullock 1980 on rent-seeking; Lazear and Rosen 1981 on tournaments; Hillman and Samet 1987; Hillman and Riley 1989; Baye et al. 1996 on all-pay auctions) assumes that competitive actions are one-dimensional and affect the "output" or "performance" in the contest positively. Allocation of prizes among the contestants depends on all of the contestants' performances and, hence, on the contestants' actions. Typically, better performance relative to others makes a contestant more likely to receive a larger prize.

To formalize these arguments, suppose there are $N$ risk-neutral contestants indexed by $i \in\{1, \ldots, N\}$. Each contestant chooses an action or "effort" $e_{i}$. To simplify the exposition, we follow the path of most papers on theoretical contest. We assume there is a single prize for the winner that is valued at $w_{1 i}$ by contestant $i$, and $N-1$ identical (and lower valued) prizes for losers valued at $w_{2 i}$ by contestant $i$. We define the prize spread as $\Delta w_{i}:=w_{1 i}-w_{2 i}$. Contestant $i$ receives the winner's prize with probability $p_{i}=p_{i}(\boldsymbol{e}) \in[0,1]$, where $\boldsymbol{e}=\left(e_{1}, \ldots, e_{N}\right)$ denotes the vector of contestants' efforts and $\sum_{i} p_{i}=1$. $p_{i}$, often termed a "contest success function" in the literature, which is nondecreasing in $e_{i}$, and non-increasing in $\boldsymbol{e}_{-i}=\left(e_{1}, \ldots, e_{i-1}, e_{i+1}, \ldots, e_{N}\right)$. Contestant $i$ chooses his action to maximize his expected payoff:

$$
\pi_{i}=w_{2 i}+p_{i}(\boldsymbol{e}) \Delta w_{i}-c_{i}\left(e_{i}\right),
$$

where $c_{i}\left(e_{i}\right)$ is the cost of his action. Stronger action (i.e., more effort) is assumed to be more costly; thus $c_{i}^{\prime}>0$.

In many applications, no between-contestant asymmetry in prize valuations is assumed, i.e., $w_{1 i}=w_{1}$ and $w_{2 i}=w_{2}$, and, as a result, $\Delta w_{i}=\Delta w$ for all $i$. In most of this discussion we will adopt the same assumption, while noting any exceptions.

From Eq. (1), it is easy to see that a contestant faces a simple tradeoff when deciding his optimum effort. By exerting more effort, he can increase his probability of receiving the winner's prize. However, he also increases the cost associated with the effort. The optimum effort depends on the contest design chosen in the first stage. The prize spread, for example, affects a contestant's gain from outperforming his rivals and thus his optimum effort. In many applications it is assumed that the organizer receives some payoff, which depends on the vector of efforts, but has to pay for the contest's prizes. Thus, he may wish to design the contest in such a way as to maximize the difference between the payoff and the sum of contest prizes.

\section{Rationale behind sabotage in contests}

As already indicated, the allocation of prizes in contests typically depends on the contestants' relative performances. Therefore, the probability of receiving the winner prize could be increased either by boosting one's own performance (e.g., by choosing to exert more effort, as argued in the preceding section) or by damaging the performances of other contestants. If such destructive behavior is feasible, competitive activities are $\mathrm{N}$-dimensional and given by $\left(e_{i}, s_{i}\right)$ with $s_{i j}(j=1, \ldots, N, j \neq i)$ being the action that contestant $i$

\footnotetext{
${ }^{4}$ In some applications, for example war, there is no contest designer. In some other cases, such aspects are beyond the contest organizer's control. When parties lobby for a government license, for example, the winner's prize is the profit that can be earned by being awarded the license. In both of these situations, the game consists of only one (namely, the second) stage.
} 
takes to reduce contestant $j$ 's performance and $s_{i}=\left(s_{i 1}, \ldots, s_{i i-1}, s_{i i+1}, \ldots, s_{i N}\right) .^{5}$ In turn, the probability of receiving the winner's prize would have to be restated as $p_{i}(\boldsymbol{e}, \boldsymbol{s})$, with $\boldsymbol{s}=\left(\boldsymbol{s}_{1}, \ldots, \boldsymbol{s}_{N}\right)$. This probability is non-decreasing in $\boldsymbol{s}_{i}$, but non-increasing in $\boldsymbol{s}_{-i}=\left(s_{1 i}, \ldots, s_{i-1 i}, s_{i+1 i}, \ldots, s_{N i}\right)$. Dye (1984) and Lazear (1989) were the first economists to take into account such destructive behavior in contests. They denote the actions $s_{i j}$ as sabotage directed by contestant $i$ against contestant $j$. Again, it is typically assumed that performing these actions is costly. Among their other components, those costs may include punishment for detected sabotage, costs of hiding sabotage acts, and effort expended in implementing sabotage. Thus, the total costs now amount to $c_{i}=c_{i}\left(e_{i}, \boldsymbol{s}_{i}\right){ }^{6}$ Taking these arguments into account, the payoff function in Eq. (1), specified in the preceding section, changes to:

$$
\pi_{i}=w_{2}+p_{i}(\boldsymbol{e}, \boldsymbol{s}) \Delta w-c_{i}\left(e_{i}, \boldsymbol{s}_{i}\right) .
$$

When deciding on sabotage activities, a contestant faces a tradeoff similar to that associated with productive efforts. By sabotaging his opponents, the contestant increases his probability of winning but also his own costs. Therefore, the theoretical prediction is that contestants may well find it in their interest to sabotage others. ${ }^{7}$

Whether people in the field behave in accordance with this prediction can be answered only by studying data on behavior in contests. Unfortunately, sabotage activities are rarely recorded, so field studies of sabotage (except in sports) are, basically, absent. An early exception is the paper by Drago and Garvey (1998). They conducted a survey of Australian employees and found that employees tend to help each other less if their own compensation depends on relative performance. As sabotage can be understood as the opposite of help (because sabotage reduces another contestant's performance, whereas help increases it), their findings imply that sabotage is empirically relevant. This conclusion is confirmed by numerous laboratory experiments (Harbring and Irlenbusch 2004, 2005, 2008, 2011; Harbring et al. 2007; Falk et al. 2008; Vandegrift and Yavas 2010; Carpenter et al. 2010; and Gürtler et al. 2013), and field studies from sports (Balafoutas et al. 2012; Brown and Chowdhury 2014; Deutscher et al. 2013).

\section{Welfare effects of sabotage}

The examples listed in the Sect. 1 are anecdotal evidence of sabotage, and the studies cited in the previous section establish that sabotage is empirically relevant also. These observations prompt investigation of the effects of sabotage on a contest's outcome, especially its welfare implications. The act of sabotage has several consequences, but it in general

\footnotetext{
5 This specification excludes the term $s_{i i}$, i.e., the possibility of sabotaging oneself. Although "self sabotage" may seem improbable, Gürtler et al. (2013) show that it is rational for a contestant in some special circumstances to sabotage himself. We discuss this issue again in the Sect. 4.1.

6 Beviá and Corchón (2006) is an exception. They assume that contestants share the aggregate output they produce and that their shares depend on the relative contributions to total output. By sabotaging the other contestants, a contestant increases his relative contribution while at the same time total output declines. Hence, sabotage can generate indirect and direct costs.

7 Standard procedures exist to show the existence of equilibria and to characterize them, given specific forms of the CSF and the cost function. We describe some in detail in the Sect. 5. In addition, it is easy to see that contestants are more inclined to sabotage others if the probability of winning the prize is very sensitive to sabotage efforts. We revisit this issue in the Sect. 5 .
} 
affects welfare adversely. It is easy to observe that the resources expended on sabotage behavior are unproductive and hence wasteful. In addition, by definition, the purpose of sabotage activities is to reduce rivals' productive performance, thereby destroying valuable output. Although these consequences of sabotage are either a direct implication of our model or evident without further explanation, the remaining consequences deserve further elaboration.

The expectation of being sabotaged has a discouragement effect, which causes the participants to reduce their productive efforts. In extreme cases, sabotage may lead to adverse selection of contestants in the sense that the best possible participants might refrain from participating altogether. In the Sect. 4.1, we first determine who suffers the most from sabotage and then investigate the effects of sabotage on welfare. We consider several other perspectives on the effects of sabotage. Sabotage may prevent the contest organizer from allowing proper information flow. If affirmative action policies increase sabotage, the organizer may be apprehensive about using such policies. Agents who do not actively participate in the contest, for example spectators in sports contests or voters in an election, can also be adversely affected if sabotage occurs. We discuss such issues in the Sect. 4.2. Finally, in the subsequent section, we briefly address the welfare effects of sabotage when regular efforts are themselves unproductive, such as in rent-seeking contests.

\subsection{Victims of sabotage and related consequences}

Many studies of sabotage in contests either consider situations with two contestants or focus on symmetric equilibria in which all contestants are subject to the same amount of sabotage. However, if a contestant faces at least two opponents, he may decide to reduce one contestant's output more strongly than another one's. In those circumstances, the question which arises is: Which contestant is subject to the most sabotage?

One aspect of this question is the possibility of heterogeneity among contestants. A contestant would be indifferent to sabotaging different rivals if they were homogenous. ${ }^{8}$ Heterogeneity may either occur ex ante, i.e., contestants may inherently be different in terms of efficiency, or it may occur ex post, i.e., in a multi-stage contest, one (ex-ante homogenous) contestant might perform better in the early rounds than his rivals. Ex-ante heterogeneity, under risk neutrality, can easily be captured by heterogeneity in prize values. If $\Delta w_{i}>\Delta w_{j}$, it can be said that contestant $i$ is more efficient than contestant $j$.

Determining optimal shooting strategies in truels (shooting contests between three contestants), Shubik (1954) indicated that the best shooter may not necessarily survive the truel with the highest probability. This is because the other two contestants may focus their attention on the best shooter to eliminate him early from the contest. Similar logic has been proven to be true in the context of sabotage. In contests with at least three contestants, very able contestants are often sabotaged more heavily because they present the greater danger. ${ }^{9}$

To capture this argument formally, we put some additional structure on $p_{i}$. Suppose that each contestant's performance is denoted by $y_{i}$, which is a function of $e_{i}$ and $\boldsymbol{s}_{-i}$. Assume, also, that contestant $i$ receives the top prize if and only if his performance is better than all

\footnotetext{
${ }^{8}$ Of course, the contestant may find it optimal to sabotage more than one rival, in which case, typically, he would sabotage homogenous rivals equally. The decision to sabotage one or multiple rivals depends, among other things, on whether there are increasing or diminishing returns to sabotaging a single rival.

9 See, for instance, Skaperdas and Grofman (1995), Chen (2003), Yumoto (2003), Münster (2007) or Gürtler and Münster (2010). Regarding the example of the Satin bowerbirds in the Sect. 1, it is observed that bowers artificially decorated with exaggerated numbers of berries are subject to more destruction (Madden 2002).
} 
other contestants'. Then, $p_{i}$ can be restated as $p_{i}=P\left(y_{i}>\max \left\{y_{1}, \ldots, y_{i-1}, y_{i+1}, \ldots, y_{N}\right\}\right)$, where $P(\cdot)$ denotes the probability operator. Suppose that contestant $i$ believes that contestant $j$ is so able that $j$ will beat all of $i$ 's other opponents or, in other words $\max \left\{y_{1}, \ldots, y_{i-1}, y_{i+1}, \ldots, y_{N}\right\}=y_{j}$. Then, $p_{i}$ simplifies to $p_{i}=P\left(y_{i}>y_{j}\right)$, and $i$ finds it optimal to sabotage contestant $j$ only (because $\frac{\partial p_{i}\left(\boldsymbol{e}^{*} \boldsymbol{s}^{*}\right)}{\partial s_{i k}}=0$ for all $k=1, \ldots, N, k \neq i, j$ ), if he wants to sabotage anyone at all. ${ }^{10}$

The consequences of sabotage for the contest's organizer can be disastrous. Talented contestants may not want to participate in the contest at all if they expect sabotage (Münster 2007). The contest's organizer may thus be left with mediocre contestants. This type of adverse selection is particularly detrimental if the efforts exerted by the best contestants are pivotal in determining social welfare. Examples of such incidences are patent races or innovation tournaments with spillovers. In such situations, the greatest effort usually is correlated with a better quality product or process, and the act of sabotage may potentially degrade that quality.

Another consequence of the threat of sabotage is that in the early rounds of dynamic contests, contestants may not want to devote much productive effort to avoid gaining a lead and thereby becoming the victim of sabotage in later rounds (Gürtler and Münster 2010). Gürtler and Münster (2013) obtained an even stronger result. They assume that contestants suffer psychologically from being sabotaged by others. Consequently, the contestants may decide to help others in the early rounds of a dynamic tournament or even engage in selfsabotage so as not to be targeted by the sabotage efforts of others in later rounds. Hence, the problem of sabotage may lead to an additional problem of demotivation. It should be noted, however, that the results are valid only if none of the competitors is beyond the reach of the other competitors before the final period begins. Otherwise, the winner of the tournament would be known before the start of the final round and sabotaging others would no longer make sense.

These theoretical findings are well supported by experimental studies. Gürtler et al. (2013) conducted experiments on dynamic three-person contests and found that contestants with a lead at the beginning of the final round were sabotaged more heavily than contestants who were not in a leading position. They also confirmed that the prospect of being sabotaged at a later stage of the game reduces the incentive to work productively early on. A similar observation was made by Carpenter et al. (2010). In the experiment of Carpenter et al. (2010), a competitor's opponents evaluated his performance subjectively. Contestants can sabotage other contestants by under reporting those contestants' performances. Carpenter et al. (2010) found that subjects indeed under reported rivals' performances, and this had a negative effect on incentives.

An interesting result was obtained by Deutscher et al. (2013). In a theoretical model, they found that the more able contestants were sabotaged to a greater extent even in static two-contestant contests. The result depends on the assumption that the more able contestants have higher returns for productive effort, and productivity and sabotage are substitutes for each other. Because of the first assumption, less able contestants exert less productive effort; this, with the second assumption, implies more sabotage. The authors tested their predictions by using data from German professional soccer matches and

\footnotetext{
${ }^{10}$ Beviá and Corchón (2006) investigated whether agents decide to sabotage others at all (i.e., whether the equilibrium is interior). In line with the above arguments, they show that if an agent is unwilling to sabotage another agent of some specific ability, he also does not sabotage any other agent of lesser ability.
} 
obtained results in agreement with their theoretical findings. ${ }^{11}$ Vandegrift and Yavas (2010) conducted laboratory experiments studying two-person contests and found that better contestants were sabotaged more vigorously.

However, it is also theoretically possible that the best contestants are not sabotaged as much or as often and the stated problems do not materialize. Gürtler and Münster (2010) showed that contestants may want to sabotage weak contestants in the early rounds of dynamic contests to eliminate them from the competition. Amegashie and Runkel (2007) considered a four-person (and thus two-stage) elimination contest. They found that the most able contestant may decide to help the weakest contestant (and thus sabotage the stronger contestant) in the other semifinal, whereas all other contestants only take actions that affect the outcome of their own semifinal. Finally, Gürtler (2008) considered a contest between two teams. He showed that it may be optimal to direct all sabotage activities against the weakest member of the opponent team. If team production is characterized by decreasing returns to effort and complementarities exist between individual efforts, this type of sabotage strategy reduces the opponent team's output most effectively.

Balafoutas et al. (2012) and Dato and Nieken (2014) investigated the personal characteristics of contestants who are likely to be sabotaged. Balafoutas et al. (2012) analyzed the interactions between ability and gender in sabotage decisions in judo world championships. Destructive strategies in judo, called "Shido", are "intended to hinder the opponent's attack" and are penalized if "judged to be against the rules of the game". ${ }^{12}$ Balafoutas et al. (2012) classifies "Shido" as sabotage and found it was used more by contestants with low world rankings and used most against contestants with high world ranking. However, no significant difference was found in sabotage behavior by gender. Instead of studying the effect of ability on sabotage, Dato and Nieken (2014) specifically investigated whether gender differences exist in sabotage behavior. In a real-effort experiment they observed that men sabotage their opponents more than women do. In turn, in a mixed tournament between men and women, women were sabotaged more than men. Therefore, although men were more likely to win the tournament they also incurred higher sabotage costs. These two effects more or less even out, and the expected payoffs are similar for men and women.

\subsection{Other welfare effects of sabotage}

As we elaborate in this subsection, sabotage may also affect welfare by reducing the benefits from specific policies, for example performance feedback and affirmative action, and by reducing the utility of third parties not actively participating in the contest. Charness et al. (2014) conducted a between-subject laboratory experiment to understand the possible effect of sabotage in situations wherein subjects received a fixed (i.e., performance-independent) wage. In different treatments, the subjects were required to perform a task requiring real effort. In one treatment, participants were not given any feedback about their relative performances whereas in another treatment, they were so informed. In

\footnotetext{
11 See also Ishida (2012) and Balafoutas et al. (2012). In a model with private abilities, Ishida (2012) found that very able contestants who signal their ability early on are sabotaged more in two-contestant contests. Balafoutas et al. (2012) analyzed data from judo matches and found that higher-ranked contestants were sabotaged more often.

12 Because "Shido" is used to reduce the effectiveness of the opponent's productive activity and is costly (owing to the possible penalty), by definition it is sabotage. Similarly, in soccer a "foul" (Corral et al. 2010; Deutscher et al. 2013) and in horse racing an "intervention" (Brown and Chowdhury 2014) are regarded as acts of sabotage.
} 
an additional treatment with feedback, subjects had the opportunity to expend resources to impair the performances of other participants (and hence to improve their relative ranking). It was found that although no explicit incentive to exert any productive effort existed, subjects actually expended effort in all treatments. Providing feedback improves performance significantly. However, when the subjects had the opportunity to sabotage each other, the final outcome was characterized by significantly less effort than in the treatment with feedback, but with no sabotage. This happens for two reasons: first, the subjects' performance is reduced by sabotage, and, second, subjects expecting sabotage exert less effort.

Affirmative action, for example handicapping some contestants or providing others with head starts are often used in a variety of contests to help contestants from disadvantaged groups. In our notation, affirmative action manipulates the function $p_{i}(\boldsymbol{e}, \boldsymbol{s})$, increasing a disadvantaged contestant's chances of winning and thereby inducing him to exert greater effort. ${ }^{13}$ However, differentially favorable treatment of some subjects may also cause more sabotage, offsetting any welfare gains from affirmative action. Brown and Chowdhury (2014) considered a contest in which the designer used policy tools to make the contest more equal for the contestants. They used data from the British Horse Racing Association. In a standard race, every horse is required to carry a minimum weight. In handicapped races, intended to make the contestants more "even", higher-ranked horses carry more weight than other horses. The authors showed that the handicap works in the right direction, in the sense that it reduces the likelihood of the highest-ranked horse winning. The authors then included the possibility of sabotage. Often, a jockey intentionally bumps his horse into another one, impedes the paths of other horses on the track, or runs his horse dangerously to reduce the likelihood of other horses winning. Classifying these incidents as sabotage, the authors found that handicapping increases the likelihood of sabotage. Brown and Chowdhury (2014) concluded that handicaps, head starts, or any other affirmative action policy tool intended to make the contest more equal should be used with caution because they can initiate and escalate sabotage behavior.

These studies illustrate that the existence of sabotage may make policies such as affirmative action and information disclosure less effective. However, given the possibility of sabotage, whether total welfare is higher with the policies (compared with when the policies are not in place) is unclear.

It is also conceivable that sabotage affects people not actively participating in the contest. It is often argued that sabotage is not only illegal but also unethical and immoral. Baumol (1992) considered an innovation race in which one firm can sabotage the R\&D efforts of a rival. This not only reduces the profit of the rival, but potentially also social welfare gains stemming from the innovation and related positive externalities. Preston and Szymanski (2003) argued that because the results in most sport contests depend on relative performance, sabotage may be an effective way of beating others, especially when the number of contestants is small. However, sabotage may also reduce the attractiveness and productivity of the contest, thereby reducing one's expected return and leaving the overall effect ambiguous.

Balafoutas et al. (2012) showed that sabotage indeed reduces the utility of spectators in a sporting match. A survey of spectators in the judo world championship shows that an

\footnotetext{
${ }^{13}$ Brown (2011) shows that differences in ability might discourage less skilled contestants and thus lessen the overall effort exerted in the contest. To address this issue, contest designers often handicap the more able contestants or give head starts to the contestants with lesser ability, for example, helping historically disadvantaged demographic groups in college admissions, the labor market, and in on-the-job promotions.
} 
increase in "fouls" reduced the spectators' utility obtained from watching the match. One should consider, however, that the spectators' disutility from increases in destructive effort and disutility from decreases in productive effort (owing to more sabotage) may be correlated. Whether the effect of destructive effort is significant, apart from the "trickle down" effect of less productive effort, is an empirical question; Balafoutas et al. (2012) did not try to answer this question.

This third-party effect is prevalent in electoral contests in which it is possible for political parties to resort to counterproductive acts such as vote rigging, vote snatching, and political violence, to gain power or to prevent the opposition's supporters voters from voting. In a political economy context, Chaturvedi (2005) showed that the party with less political support will engage in more sabotage, which may reduce the general population's confidence in democratic processes, including that of voters and non-voters alike.

Similarly, it can be hypothesized that negative campaigning in markets or in elections may reduce the utilities of consumers and voters. We found no academic research in economics that investigated the effects of negative product advertising on consumer welfare. In contrast, both theoretical and empirical studies document the effects of negative political campaigns on voters. With regard to the effect of negative campaigning on voter turnout, the demobilization hypothesis states that negative campaigns depress voter turnout whereas the stimulation hypothesis suggests that exposure to negative campaigns may even increase voters' probability of voting. The field results, however, are inconclusive.

Soubeyran (2009) showed that sabotage may affect voters negatively, resulting in lower voter turnout. He proposed a theoretical model of contest with attacks and defenses. In this model, two candidates choose between enhancing their own image (defense) and sabotaging the opponent's (attack). Soubeyran (2009) concluded that the effect of a negative advertising campaign on voter turnout depends on voter sensitivity to messages that attack a candidate's opponents. More specifically, when voter sensitivity to attack increases, candidates attack more, but the relationship between attack and voter turnout may be nonmonotonic. The empirical evidence is mixed. Ansolabehere et al. (1994) found that exposure to negative advertisements reduced intention to vote. Freedman and Goldstein (1999), however, obtained data on the frequency of an advertisement being aired and on viewership to derive an estimate of advertisement exposure. They found that exposure to negative campaign advertisements seems to increase the probability of voting. Inconclusive results were obtained when they used a different measure of individual perception of the tone of campaign advertisements.

One final, relatively uninvestigated aspect of the negative welfare effects of sabotage is the costly investments undertaken to counteract sabotage by one's opponents. This may include defensive efforts to prevent sabotage in the first place, for example investment in security measures to prevent the theft of information since the "Watergate scandal", as discussed in the Introduction, or a nation's investment in counter-terrorism measures. These defense-against-sabotage costs are welfare-reducing because they are unproductive. Gordon et al. (2005), reporting to the FBI, showed that US firms spend 8-24\% of their IT budgets on data security measures, whereas state governments may spend up to $\$ 350$ per employee annually to protect against potential threats. Hence, although it has not been investigated thoroughly, the welfare effects of this type of sabotage can be significant.

\subsection{Welfare effects of sabotage when subjects' efforts are unproductive}

Up to this point we assumed that efforts expended by contest participants are productive and that the tournament organizer thus wishes to induce high effort (as in business 
organizations and in sports). In some applications, for example rent seeking or conflict, however, contestants' efforts are themselves directly unproductive. In rent-seeking contests, effort is devoted solely to obtaining a larger share of an existing rent and is, thus, a complete waste of resources (Tullock 1967, 1980; Bhagwati 1982). In such situations, some of the previous welfare implications are reversed and sabotage may even be beneficial from that perspective. The intuition is that the prospect of being sabotaged may reduce the motivations of contestants to exert effort, as argued in the literature (Gürtler and Münster 2010; Amegashie 2012), which would lead to a welfare gain. Two examples illustrate this point.

1. Consider a firm in which several employees compete for promotion. In many instances, the promotion decision is made by the employees' superior. Therefore, employees may work extremely hard to impress the superior with their outstanding performance. Alternatively, they may simply spend time and effort trying to influence the superior's decision, urging the superior to consider them for promotion or even bribing him. ${ }^{14}$ If an employee repeatedly engages in such influence activities, it is conceivable that the other employees competing for the promotion will start to sabotage this employee. This, in turn, may discourage the employee from trying to influence the superior's decision by unproductive means, implying a welfare gain.

2. In political competition, politicians may supply inaccurate information to voters or may even tell lies to improve their chances of being elected. Exposing lies or inaccurate information could be understood as a particular form of sabotage that may be seen as very useful from society's perspective. Not only does this type of sabotage provide valuable information to voters so that they can make better voting decisions, but it also reduces the incentive to lie or provide inaccurate information in the first place.

\section{Policies to restrict sabotage}

A clear understanding of the occurrence and the consequences of sabotage allows one to design appropriate policies to overcome such issues. In this section, we address policies that economists have proposed as possible solutions to the problems related to sabotage. To understand these policies fully, it is helpful to take a closer look at the contestants' optimal sabotage activities. If we assume that an interior solution to the contestants' maximization problem exists and that the payoff functions are strictly concave, optimal sabotage activity $s_{i j}^{*}$ is characterized by the condition:

$$
\frac{\partial p_{i}\left(\boldsymbol{e}^{*}, \boldsymbol{s}^{*}\right)}{\partial s_{i j}} \Delta w=\frac{\partial c_{i}\left(e_{i}^{*}, \boldsymbol{s}_{i}^{*}\right)}{\partial s_{i j}},
$$

which simply states that $s_{i j}^{*}$ is chosen such that the marginal benefit to increasing $s_{i j}$ (in terms of a higher probability of receiving the winner's prize) equals the marginal cost of effort. Hence, policies intended to tackle the sabotage problem affect a contestant's decision by either reducing the marginal benefit from sabotaging opponents or, similar to the famous argument by Becker 1968, by increasing the (marginal) cost. We also discuss other policies besides these two that may be implemented to restrict sabotage.

${ }^{14}$ Such influence activities were studied by Milgrom (1988). 


\subsection{Policies that reduce the benefits from sabotage}

Let us begin with policies intended to reduce contestants' benefit from sabotage. The most obvious policy in this respect, proposed by Lazear (1989), is to narrow the difference between the winning and losing prizes. If this gap is reduced, contestants have less incentive to win the contest. As a result, they are less willing to engage in costly sabotage. ${ }^{15}$ Formally, with a narrower prize spread, the left-hand-side (LHS) of Eq. (3) becomes smaller and so must the right-hand-side (RHS), i.e., $\frac{\partial c_{i}\left(e_{i}^{*} s_{i}^{*}\right)}{\partial s_{i j}}$. Assuming $c_{i}$ to be strictly convex, this implies a decrease in $s_{i j}^{*}$. Similarly, however, contestants are less willing to expend productive effort. Thus, the policy comes at a cost to the contest organizer. Because of this cost, Drago and Turnbull (1991) proposed not organizing any tournament if sabotage is a serious threat (i.e., to set the prize spread equal to zero) and to seek alternative ways of motivating the contestants to expend productive effort. Bose et al. (2010) advanced a similar argument. As already explained, however, experimental results obtained by Charness et al. (2014) suggested that sabotage may occur if information regarding the contestants' performance ranking is available, even if the monetary rewards do not depend on this ranking.

These predictions of the effects of prize spread on contestants' decisions have found strong support in empirical and experimental studies. Garicano and Palacios-Huerta (2014), for example, analyzed the effects of an increase in the number of points awarded for a win in Spanish football. They found that teams react by increasing both the number of attackers and the number of defenders (while reducing the number of midfielders) in the starting lineup. They interpreted this observation not only as evidence of more vigorous productive efforts (attackers) but also of more sabotage (defenders) in response to the change in incentive structure. In agreement with the latter argument, the authors also found that the number of fouls committed increased after the change in the prize structure.

Corral et al. (2010) conducted a similar analysis with data from the 1994-1995 and 1995-1996 seasons of the Spanish Football League First Division. Again, the effects on sabotage activities of the change in the winning team's league points from two to three were investigated. Corral et al. (2010) predicted a rise in players' defensive efforts as the reward increased, and thus a greater likelihood of a player being sent off the pitch. They found that when reward points increase, teams in the winning position are more likely to sabotage and to have a player disqualified from the game. Their results also suggested that when the goal difference in a match becomes larger, the likelihood of a sending-off is usually smaller. $^{16}$

Laboratory experiments conducted to analyze the problem of sabotage in contests confirmed the observation that sabotage levels increase with increasing prize spread (Harbring and Irlenbusch 2004, 2005, 2011; Vandegrift and Yavas 2010). Contest organizers seem to understand the relationship between prize spread and sabotage level. As a result, they widen prize spread and prefer tournament schemes to other incentive devices more often if sabotage is not feasible (Falk et al. 2008; Harbring and Irlenbusch 2011).

\footnotetext{
15 As shown by Chen (2003), it is also conceivable that the level of sabotage does not depend on the prize spread at all. However, this happens only under very restrictive assumptions about production and cost functions. See Proposition 4 in his paper and the discussion thereafter.

16 This implies that a larger ex-post performance difference reduces sabotage. This result is in agreement with that from the study by Brown and Chowdhury (2014), who observed less sabotage in horse racing when the ex-ante ability difference was large. Overall, these studies suggest more sabotage between contestants with similar (ex-ante or ex-post) abilities.
} 
A second method of reducing contestants' benefits from sabotage is to increase the number of contestants. This possibility was first described by Konrad (2000). The argument goes as follows: if a contestant increases his productive effort, he increases his own output and thereby the probability of outperforming every other opponent. If, instead, he increases the level of sabotage directed against a particular rival, he reduces that rival's output and, hence, he increases the probability of outperforming that rival only. If the number of contestants is increased, productive efforts become relatively more attractive compared with sabotage activities, and the sabotage problem is mitigated. Stated differently, sabotage directed against contestant $j$ by contestant $i$ constitutes a public good for all other contestants. This is because contestant $i$ increases all other contestants' (except $j$ ) winning probabilities by sabotaging contestant $j$. Hence, the provision of the public good, i.e., sabotage, declines when more contestants participate in the game.

To present this argument formally, recall that in many situations it is assumed that contestant $i$ receives the winner's prize if and only if his performance is the best overall, so that $p_{i}=P\left(y_{i}>\max \left\{y_{1}, \ldots, y_{i-1}, y_{i+1}, \ldots, y_{N}\right\}\right)$. When worker $i$ chooses greater productive effort (i.e., when he increases $e_{i}$ ), the term on the LHS of the inequality in parentheses increases, making it more likely that $y_{i}$ exceeds any of the $y_{j}$ $(j=1, \ldots, N, j \neq i)$. Instead, when worker $i$ decides to sabotage worker $j$ more than others (i.e., when he increases $s_{i j}$ ), $y_{j}$ declines and it becomes more likely that $y_{i}$ exceeds $y_{j}$. The probability with which $y_{i}$ exceeds any of the other contestants' performances, however, is not affected. It immediately follows that the larger the number of contestants competing for the prize, the greater is the benefit from increasing $e_{i}$ relative to increasing $s_{i j}$.

Amegashie (2012) used sabotage in a rent-seeking model in a different fashion. Similar to Harbring et al. (2007), he introduced a two-contestant Tullock contest with two stages. In the first stage, the contestants can expend costly resources to increase the marginal cost of their rival. In the second stage, given their marginal costs, they expend effort in a standard Tullock contest. The difference between this model and most of the relevant literature is that the sabotage does not affect the effort of the rival directly; instead, it affects the rival's performance by increasing his cost of exerting effort. Amegashie's results confirmed the idea that sabotage is less relevant in larger contests with many participants. Although closed-form solutions for the general case of $n$ contestants are impossible to derive, numerical simulations show that in large contests, contestants do not expend positive sabotage effort.

Despite the importance of this theoretically robust argument, there is little evidence of the effects of the number of contestants on sabotage activities. Harbring and Irlenbusch (2008) found that tournament size does not affect sabotage activity. However, in their experiment, sabotage reduced the output of all of the opponents. As a result, the publicgood problem outlined earlier disappears in such a setting.

Finally, Chen (2005) considered a specific form of contest: one in which the contestants are employees who compete for promotion to a vacancy in a higher tier of their firm's hierarchy. He showed that the firm may want to consider external candidates for the vacancy if the internal candidates perform poorly. If external candidates are admitted, the return for productive effort compared with sabotage increases for the internal contestants. The reason is simple and is related to the arguments concerning contest size. By exerting productive effort, an employee improves his chances of outperforming both internal and external candidates. Sabotage, however, can be directed only against internal competitors. Hence, if the firm considers external candidates for promotion, internal competitors substitute productive effort for sabotage. Formally, this argument could be substantiated by 
writing $p_{i}$ as $p_{i}=P\left(y_{i}>\max \left\{y_{1}, \ldots, y_{i-1}, y_{i+1}, \ldots, y_{N}, \bar{y}\right\}\right)$, where $\bar{y}$ denotes a fixed performance level that cannot be affected by the contestants.

\subsection{Policies that increase the cost of sabotage}

The most obvious policy intended to raise the (marginal) cost of sabotage, $\frac{\partial c_{i}\left(e_{i}^{*} s_{i}^{*}\right)}{\partial s_{i j}}$, is to increase the punishment when sabotage is detected. In many contests, the maximum punishment that the contest organizer can inflict on a contestant is to strip him of the prize he had won. In a setting of cheating that is analytically similar to that of sabotage, Curry and Mongrain (2009) considered such a situation and investigated whether stripped prizes should be re-awarded to other contestants. They demonstrated that re-awarded prizes mitigate the wrongdoing. In the context of sabotage, if prizes are re-awarded, a contestant can expect to improve his relative ranking and to obtain a larger prize if other contestants whose sabotage activities have been detected are disqualified. By engaging in sabotage himself, the contestant risks missing the opportunity to receive a larger prize "for free", making sabotage a costly activity.

Several other policies intended to increase the cost of sabotage have been discussed in the literature. Lazear (1989) proposed separating contestants spatially to make it more difficult for them to sabotage each other. Consider the example of a firm that organizes a contest to motivate employees. Employees from different locations would find it harder to affect their opponents' performances than employees working in the same building or office.

When the contest organizer is able to influence the contestant field ex ante, he may choose to let in only those for whom sabotaging others is relatively costly. Participants may incur some form of psychological cost while sabotaging others and this cost may vary. Similarly, participants who suffer from relative deprivation or envy when worse off than others incur lower costs of sabotage because sabotage reduces the probability of feeling deprived or envious (Kräkel 2000; Grund and Sliwka 2005). The contest organizer thus should admit only those participants who do not suffer from relative deprivation or envy. Unfortunately, it is often difficult to observe the specific characteristics of a participant, especially their states of mind. Furthermore, participants do not have an incentive to selfselect into contests that are designed for their types (Lazear 1989). Mechanisms such as assessment centers may help to screen contestants, but those assessments will be far from perfect.

Balafoutas et al. (2012) reported the results of a field study of the effects of sabotage costs. They relied on data from two consecutive judo world championships in 2007 and 2009 to analyze the effects of the cost structure on the use of sabotage. They specified productive activities (attacking strategies) and sabotage activities (defensive strategieswhich are often penalized) in judo. A change in judo's rules in 2009 allowed the contestants to commit one act of "sabotage" without penalty, hence reducing the cost of sabotage. Balafoutas et al. (2012) found that, as expected, the reduction in cost increased the total number of sabotage acts. Hence, it is suggested that when it is possible to monitor sabotage and impose costs upon it, a heavy penalty cost should be imposed.

Laboratory experiments have found that contestants retaliate when sabotaged and that the threat of retaliation deters contestants from sabotaging others in the first place (Harbring et al. 2007; Vandegrift and Yavas 2010). Retaliation thus acts as a type of additional indirect cost of sabotage. Of course, contestants must learn the identity of saboteurs to be able to retaliate against them. The contest should therefore be transparent in the sense that 
sabotage decisions should be observable publicly. Moreover, contestants should meet each other more than once to be able to retaliate. Retaliation, however, may not just benefit the contest organizer; it may also be used against him. If he treats the contestants badly, they may decide to sabotage each other to reduce the output that the contest organizer receives. This type of behavior was observed by Harbring and Irlenbusch (2005). They found that sabotage is more frequent if the organizer himself sets low prizes rather than if these low prizes are determined exogenously. Presumably, the psychological costs of sabotaging others are higher if the contestants were treated well by the contest organizer than if they were not. An immediate conclusion is that the organizer should be generous toward the contestants to prevent them from engaging in sabotage. Finally, experimental results from Bolle et al. (2014) showed that if retaliation itself can be retaliated against, contestants might engage only in destructive behavior, i.e., retaliation against a saboteur might escalate the execution of destructive behavior in an upward spiral over time and lead to the worst possible outcome. Hence, the designer will need to be very careful about allowing retaliatory actions.

The contest organizer may instead wish to affect the timing of sabotage decisions. Kräkel (2005) considered a model in which participants decided to help or sabotage each other first and, after having observed those decisions, choose their productive efforts. He showed that a contestant may even want to help his opponent to make subsequent competition less equal and thus less intense. In other words, sabotaging the opponent would yield a close competition in productive effort and, accordingly, raise the cost of productive effort. To reduce this cost, participants may abstain from sabotaging the opponent. Of course, the reduction in sabotage comes at a cost to the contest organizer because, in contrast with the contestants, he suffers from the reduction in productive efforts.

\subsection{Other policies}

Policies to restrict sabotage exist that do not fall into either of the two categories described above. Brown and Chiang (2008), for instance, considered the tournament setting of Lazear (1989) and allow the competitors to form coalitions. It is assumed that positive externalities exist, implying that a coalition's probability of winning depends on its size. If such externalities are sufficiently salient, an equilibrium sub-coalition forms and sabotage activity declines overall. For a sufficiently small externality, a grand coalition exists and sabotage does not occur at all. Understandably, this type of policy may be feasible only for some specific situations and not for sports or workplace environments.

Given previous studies of sabotage, however, the most important policy may be restricting the provision of information to the contestants. Gürtler et al. (2013) argued that many of the outlined problems rely on the possibility of contestants observing each other's talents or past performances. Hence, the contest organizer should try to keep this type of information secret. If, for instance, the organizer does not reveal intermediate performance information to the contestants in a dynamic contest, they do not know which contestant has a lead and cannot direct their sabotage efforts at this particular contestant. As a result, incentives to expend productive effort in early rounds of the contest are reinstated. Using experimental data, Gürtler et al. (2013) found that this type of restrictive information policy works in the sense that productive efforts in early rounds of dynamic contests increase.

There are some limits to this argument, however. In some settings, the tournament organizer is simply unable to fully restrict the flow of information. In repeated contestants, for example, the winners of the early rounds are announced publicly and so become 
common knowledge. It is then easy to infer that the winners were the high-performing contestants so that in future contests, it will be difficult to hide information about who the top performers are. A possible way of mitigating this problem is to introduce new contestants with unknown ability periodically. As Chen (2003) argues, including contestants from outside of an organization may reduce the likelihood of sabotage.

Another possibility for tackling the problems described earlier is to change the prize structure. Suppose that a single loser prize is awarded, but the contest offers $N-1$ winning prizes. Then, $p_{i}$ is given by $p_{i}=P\left(y_{i}>\min \left\{y_{1}, \ldots, y_{i-1}, y_{i+1}, \ldots, y_{N}\right\}\right)$, and the contestants prefer to sabotage contestants of low ability to ensure they do not finish in the last position (Yumoto 2003). As a result, very able contestants are willing to participate in such a contest. Moreover, in dynamic contests, contestants have an incentive to exert high productive effort in early stages to avoid lagging behind and being sabotaged harshly.

\section{Conclusion}

Sabotage is the exertion of destructive effort toward rivals with the intention of reducing their likelihood of winning a contest. Although sabotage is observed in various day-to-day situations, for example sport, on-the-job promotions, war, and rent seeking, and, moreover, a sizeable body of literature on this topic exists, that literature has not yet been thoroughly reviewed. This article fills the gap, focusing on the economics of sabotage in contests.

Both theoretical and applied studies agree on several points regarding sabotage. Sabotage is positively related to the value of the prize to be won and negatively to the cost of engaging in sabotage activities. Usually, saboteurs are more likely to target their ablest rivals and to do so more frequently. Circumstances exist in which sabotage, whether by one competitor or a coalition of them, offsets the gains from investing productive effort in a contest. That is because sabotage directly reduces the contest's collective output, discourages contestants from exerting productive efforts, and imposes negative externalities on third parties. Sabotage may be limited in several ways, viz. increasing the cost of sabotage, concealing information regarding contestants' abilities or performances, increasing the number of participants, and not making the contest more equal for contestants with different abilities.

Sabotage has been studied extensively in the context of promotion tournaments. However, the sabotage problem may be relevant even if firms do not rely on tournaments to select employees to move up the organization's hierarchy. In many situations, firms find it in their best interest to offer wage contracts to their employees that depend on the employees' relative performances. Such wage contracts may, for instance, be optimal if individual performances are positively correlated and employees are risk-averse, so, in that case, relative performance evaluation (RPE) reduces the income risk that employees face (Holmström and Milgrom 1990). If an employee's wage depends on his performance relative to that of others, the incentive structure is similar to that in a tournament and, hence, sabotage is an issue. Sabotage may occur even if workers collaborate in teams (Auriol et al. 2002; Bose et al. 2010; Kräkel and Müller 2012).

Some interesting and relevant areas exist in which investigations relating to sabotage have yet to be conducted. The theoretical literature still needs to investigate issues of sabotage in contests with several prizes, in super games, and in dynamic and/or sequential games. The literature on issues relevant to contest design, for example seeding, prize distribution, or entry does not yet include sabotage. This is also true for contests that 
generate externalities such as networks, social preferences, and identities. Few attempts have been made to analyze sabotage in groups and in coalitions. Defensive measures against sabotage activities and the corresponding welfare implications have, likewise, not yet been studied. Most of the studies consider normal efforts in contests as welfare enhancing and sabotage as welfare reducing. If, as considered in the Sect. 4.3, contest efforts are believed to be welfare reducing, the corresponding behavioral implications will demand different welfare analysis. More fundamentally, each and every model involving sabotage possibilities assumes the overall probability of winning a prize to be fixed (at 1, for instance). However, in other cases, such as patent races, advertising, and some sporting events, this might not be true. One literature topic addresses attack-and-defense strategies (for example Grossman and Kim 1995), the analytical techniques of which are often the same as those used in analysis of sabotage. Comparisons of those two literature topics are still pending.

Current empirical evidence on sabotage activities mostly comes from laboratory experiments; the literature itself is quite limited. Issues such as sabotage in network games, the interaction between risk and sabotage, and sabotage and contest design are currently almost untouched. Interesting issues also relate to post-contest sabotage in multi-stage or dynamic contests. Whether a contestant chooses to sabotage the opponent after a contest ends to reduce future competition is an empirical question and should be investigated. The body of field evidence regarding sabotage is not large, and most of the evidence is from sports contests. It will be useful to extend such investigations to areas other than sports. As already discussed, the welfare effects of sabotage in market or political environments remain to be studied and measured. Most theoretical and applied research on sabotage focuses on the "effects" of sabotage or the "material reason" for sabotage. However, because the nature of the act itself is fundamentally behavioral, it is very important to observe the theory from the perspective of behavioral economists (for example Mui 1995). Finally, no field experiments on sabotage have yet been conducted beyond the world of sports. Hence, opportunities to extend the literature in this area are both broad and deep.

Acknowledgments We thank William Shughart II (the Editor), three anonymous referees, Atsu Amegashie, Loukas Balafoutas, Luis Corchón, Richard Havell, David Malueg, Stephen Martin, Johannes Münster, David Rojo-Arjona, Santiago Sanchez-Pages, Fangfang Tan, Iryna Topolyan, the participants at the 2015 BRiDGE Workshop on Contests in Bilbao, and the seminar participants at the University of East Anglia for useful comments. Any remaining errors are our own.

Open Access This article is distributed under the terms of the Creative Commons Attribution 4.0 International License (http://creativecommons.org/licenses/by/4.0/), which permits unrestricted use, distribution, and reproduction in any medium, provided you give appropriate credit to the original author(s) and the source, provide a link to the Creative Commons license, and indicate if changes were made.

\section{References}

Abbink, K., Brandts, J., Herrmann, B., \& Orzen, H. (2010). Inter-group conflict and intra-group punishment in an experimental contest game. American Economic Review, 100, 420-447.

Abbink, K., \& Sadrieh, A. (2009). The pleasure of being nasty. Economics Letters, 105(3), 306-308.

Amegashie, J. A. (2012). Productive versus destructive efforts in contests. European Journal of Political Economy, 28, 461-468.

Amegashie, J. A. (2015). Sabotage in contests. In R. D. Congleton \& A. Hillman (Eds.), A companion to rent seeking and political economy (pp. 138-149). Cheltenham: Edward Elgar.

Amegashie, J. A., \& Runkel, M. (2007). Sabotaging potential rivals. Social Choice and Welfare, 28, $143-162$. 
Ansolabehere, S., Iyengar, S., Simon, A., \& Valentino, N. (1994). Does attack advertising demobilize the electorate? American Political Science Review, 88, 829-838.

Auriol, E., Friebel, G., \& Pechlivanos, L. (2002). Career concerns in teams. Journal of Labor Economics, 20, 289-307.

Balafoutas, L., Lindner, F., \& Sutter, M. (2012). Sabotage in tournaments: Evidence from a natural experiment. Kyklos, 65, 425-441.

Bhagwati, J. N. (1982). Directly unproductive, profit-seeking (DUP) activities. Journal of Political Economy, 90, 988-1002.

Baye, M. R., Kovenock, D., \& de Vries, C. G. (1996). The all-pay auction with complete information. Economic Theory, 8, 291-305.

Baumol, W. J. (1992). Innovation and strategic sabotage as a feedback process. Japan and the World Economy, 4, 275-290.

Becker, G. (1968). Crime and punishment: An economic approach. Journal of Political Economy, 76, 169-217.

Beviá, C., \& Corchón, L. C. (2006). Rational sabotage in cooperative production with heterogeneous agents. B.E. Journal of Theoretical Economics (Topics), 6, 1-27.

Bolle, F., Tan, J., \& Zizzo, D. J. (2014). Vendettas. American Economic Journal, Microeconomics, 6, 93-130.

Borgia, G. (1985). Bower destruction and sexual competition in the satin bowerbird (Ptilonorhynchus riolaceus). Behavioral Ecology and Sociobiology, 18, 91-100.

Bose, A., Pal, D., \& Sappington, D. (2010). Equal pay for unequal work: Limiting sabotage in teams. Journal of Economics \& Management Strategy, 19, 25-53.

Brown, A., \& Chowdhury, S. M. (2014). The hidden perils of affirmative action: Sabotage in handicap contests. University of East Anglia AFE Working paper \#62.

Brown, J. (2011). Quitters never win: the (adverse) incentive effects of competing with superstars. Journal of Political Economy, 119, 982-1013.

Brown, M., \& Chiang, S. H. (2008). Tournaments, coalitions, and truthfulness. SSRN working paper. http:// ssrn.com/abstract $=530902$.

Carpenter, J. P., Matthews, P., \& Schirm, J. (2010). Tournaments and office politics: Evidence from a real effort experiment. American Economic Review, 100, 504-517.

Charness, G., Masclet, D., \& Villeval, M. C. (2014). The dark side of competition for status. Management Science, 60, 38-55.

Chaturvedi, A. (2005). Rigging elections with violence. Public Choice, 125, 189-202.

Chen, K. P. (2003). Sabotage in promotion tournaments. Journal of Law, Economics and Organization, 19 , 119-140.

Chen, K. P. (2005). External recruitment as an incentive device. Journal of Labor Economics, 23, $259-277$.

del Corral, J., Prieto-Rodriguez, J., \& Simmons, R. (2010). The effect of incentives on sabotage: The case of Spanish football. Journal of Sports Economics, 11, 243-260.

Curry, P. A., \& Mongrain, S. (2009). Deterrence in rank-order tournaments. Review of Law \& Economics, 5, $723-740$.

Dato, S., \& Nieken, P. (2014). Gender differences in competition and sabotage. Journal of Economic Behavior and Organization, 100, 64-80.

Dechenaux, E., Kovenock, D., Sheremeta, R.M. (2012). A survey of experimental research on contests, allpay auctions and tournaments. Chapman University Working paper.

Deutscher, C., Frick, B., Gürtler, O., \& Prinz, J. (2013). Sabotage in tournaments with heterogeneous contestants: Empirical evidence from the soccer pitch. Scandinavian Journal of Economics, 115, 1138-1157.

Drago, R., \& Garvey, G. T. (1998). Incentives for helping on the job: Theory and evidence. Journal of Labor Economics, 16, 1-25.

Drago, R., \& Turnbull, G. K. (1991). Competition and cooperation in the workplace. Journal of Economic Behavior and Organization, 15, 347-364.

Dye, R. A. (1984). The trouble with tournaments. Economic Inquiry, 22, 147-149.

Falk, A., Fehr, E., \& Huffman, D. (2008). The power and limits of tournament incentives. Discussion paper. Freedman, P., \& Goldstein, K. (1999). Measuring media exposure and the effects of negative campaign ads. American Journal of Political Science, 43, 1189-1208.

Friedman, W. A. (1998). John H. Paterson and the sales strategy of the National Cash Register Company, 1884 to 1922. Business History Review, 72(4), 552-584.

Garicano, L., \& Palacios-Huerta, I. (2014). Making the beautiful game a bit less beautiful. In I. PalaciosHuerta (Ed.), Beautiful game theory-how soccer can help economics (pp. 124-150). Princeton: Princeton University Press. 
Genakos, C., \& Pagliero, M. (2012). Interim rank, risk taking, and performance in dynamic tournaments. Journal of Political Economy, 120, 782-813.

Gordon, L. A., Loeb, M. P., Lucyshyn, W., \& Richardson, R. (2005). 2005 CSI/FBI computer crime and security survey. San Francisco: Computer Security Institute.

Grossman, H. I., \& Kim, M. (1995). Swords or plowshares? A theory of the security of claims to property. Journal of Political Economy, 103, 1275-1288.

Grund, C., \& Sliwka, D. (2005). Envy and compassion in tournaments. Journal of Economics and Management Strategy, 14, 187-207.

Gürtler, O. (2008). On sabotage in collective tournaments. Journal of Mathematical Economics, 44, 383-393.

Gürtler, O., \& Münster, J. (2010). Sabotage in dynamic tournaments. Journal of Mathematical Economics, 46, 179-190.

Gürtler, O., \& Münster, J. (2013). Rational self sabotage. Mathematical Social Sciences, 65, 1-4.

Gürtler, O., Münster, J., \& Nieken, P. (2013). Information policy in tournaments with sabotage. Scandinavian Journal of Economics, 115, 932-966.

Harbring, C., \& Irlenbusch, B. (2004). Sabotage and the endogenous design of tournaments. Discussion paper, University of Bonn.

Harbring, C., \& Irlenbusch, B. (2005). Incentives in tournaments with endogenous prize selection. Journal of Institutional and Theoretical Economics, 161, 636-663.

Harbring, C., \& Irlenbusch, B. (2008). How many winners are good to have? On tournaments with sabotage. Journal of Economic Behavior and Organization, 65, 682-702.

Harbring, C., \& Irlenbusch, B. (2011). Sabotage in tournaments: Evidence from a laboratory experiment. Management Science, 57, 611-627.

Harbring, C., Irlenbusch, B., Kräkel, M., \& Selten, R. (2007). Sabotage in corporate contests-an experimental analysis. International Journal of the Economics of Business, 14, 367-392.

Hillman, A., \& Riley, J. (1989). Politically contestable rents and transfers. Economics and Politics, 1, 17-39.

Hillman, A., \& Samet, D. (1987). Dissipation of contestable rents by small number of contenders. Public Choice, 54, 63-82.

Holmström, B., \& Milgrom, P. (1990). Regulating trade among agents. Journal of Institutional and Theoretical Economics, 146, 85-105.

Ishida, J. (2012). Dynamically sabotage-proof tournaments. Journal of Labor Economics, 30, 627-655.

Kautilya (2003). The artha shastra. Penguin Classics, Penguin Books India.

Konrad, K. A. (2000). Sabotage in rent-seeking contests. Journal of Law, Economics and Organization, 16, $155-165$.

Konrad, K. A. (2009). Strategy and dynamics in contests. Oxford: Oxford University Press.

Kräkel, M. (2000). Relative deprivation in rank-order tournaments. Labour Economics, 7, 385-407.

Kräkel, M. (2005). Helping and sabotaging in tournaments. International Game Theory Review, 7, 211-228.

Kräkel, M., \& Müller, D. (2012). Sabotage in teams. Economics Letters, 115, 289-292.

Lazear, E. P. (1989). Pay equality and industrial politics. Journal of Political Economy, 97, 561-580.

Lazear, E. P., \& Rosen, S. (1981). Rank-order tournaments as optimum labor contracts. Journal of Political Economy, 89, 841-864.

Lubin, G. (2011). Campbell's soup is still reeling from the 2008 MSG attack ads. http://www. businessinsider.com/campbells-soup-wars-citi-2011-7

Madden, J. R. (2002). Bower decorations attract females but provoke other male spotted bowerbirds: Bower owners resolve this trade-off. Proceedings of the Royal Society B, 269, 1347-1351.

Milgrom, P. (1988). Employment contracts, influence activities, and efficient organization design. Journal of Political Economy, 96, 42-60.

Mui, V. L. (1995). The economics of envy. Journal of Economic Behavior and Organization, 26, 311-336.

Münster, J. (2007). Selection tournaments, sabotage, and participation. Journal of Economics and Management Strategy, 16, 943-970.

Oremus, W. (2013). The poisonous employee-ranking system that helps explain Microsoft's decline. http:// www.slate.com

Pouget, E. (1912). Sabotage. Charles H. Kerr and Company, Chicago.

Preston, I., \& Szymanski, S. (2003). Cheating in contests. Oxford Review of Economic Policy, 19, $612-624$.

Salop, S. C., \& Scheffman, D. T. (1983). Raising rivals' costs. The American Economic Review, 73, 267-271.

Shubik, M. (1954). Does the fittest necessarily survive? In M. Shubik (Ed.), Readings in game theory and related behavior (pp. 43-46). New York: Doubleday.

Skaperdas, S., \& Grofman, B. (1995). Modeling negative campaigning. American Political Science Review, 89, 49-61. 
Soubeyran, R. (2009). Contest with attack and defense: Does negative campaigning increase or decrease voter turnout? Social Choice and Welfare, 32, 337-353.

Tullock, G. (1967). The welfare costs of tariffs, monopolies, and theft. Western Economic Journal, 5, 224-232.

Tullock, G. (1980). Efficient rent seeking. In J. M. Buchanan, R. D. Tollison, \& G. Tullock (Eds.), Toward a theory of the rent-seeking society (pp. 97-112). College Station: Texas A and M University Press.

Vandegrift, D., \& Yavas, A. (2010). An experimental test of sabotage in tournaments. Journal of Institutional and Theoretical Economics, 166, 259-285.

Veblen, T. (1921). The engineers and the price system (1963rd ed.). New York: Harbinger.

Yumoto, Y. (2003). Who is target of sabotage?: The dark side of promotion tournaments. Mimeo.

Zizzo, D. J., \& Oswald, A. J. (2001). Are people willing to pay to reduce others' incomes? Annales d'Economie et de Statistique, 39-65. 